\title{
Steroid sulfatase promotes invasion through epithelial-mesenchymal transition and predicts the progression of bladder cancer
}

\author{
YASUOMI SHIMIZU ${ }^{1}$, SATOSHI TAMADA ${ }^{1}$, MINORU KATO ${ }^{1}$, YUJI TAKEYAMA ${ }^{1}$, \\ MASAKI FUJIOKA ${ }^{2}$, ANNA KAKEHASHI $^{2}$, TATSUYA NAKATANI ${ }^{1}$, HIDEKI WANIBUCHI $^{2}$ and MIN GI $^{2}$ \\ Departments of ${ }^{1}$ Urology and ${ }^{2}$ Pathology, Osaka City University Graduate School of Medicine, Osaka 545-8585, Japan
}

Received March 13, 2018; Accepted August 17, 2018

DOI: $10.3892 /$ etm.2018.6787

\begin{abstract}
Androgen signal has been recently suggested to be associated with the progression of bladder cancer. Steroid sulfatase (STS) is a steroid sulfate activation enzyme, considered to be one of the key enzymes in the androgen signaling pathway. However, the role of STS in bladder cancer has not been elucidated. The purpose of the present study was to determine the clinical and functional significance of STS in bladder cancer. Immunohistochemical analysis of surgical specimens obtained by radical cystectomy $(n=114)$ demonstrated that overexpression of STS was associated with the invasion of bladder cancer, as evidenced by the incidence of STS-positive cancers (11.5 and $37.1 \%$ in non-muscle invasive and muscle invasive bladder cancers, respectively; $\mathrm{P}=0.003$ ). STS-positive cancer demonstrated shorter recurrence-free survival and cancer-specific survival $(\mathrm{P}=0.0027$ and 0.0030 , respectively). Furthermore, knockdown of STS significantly reduced cell migration and invasion capacities of bladder cancer cells $(\mathrm{P}<0.001$ and $\mathrm{P}=0.005$, respectively), accompanied by the upregulation of E-cadherin and downregulation of vimentin. In summary, the present study demonstrated that STS promotes the invasion capability of bladder cancer via regulation of the epithelial-mesenchymal transition, and may be a useful marker for predicting the progression of bladder cancers.
\end{abstract}

Correspondence to: Dr Minoru Kato, Department of Urology, Osaka City University Graduate School of Medicine, 143 Asahimachi, Abeno, Osaka 545-8585, Japan

E-mail: kato.minoru@med.osaka-cu.ac.jp

Abbreviations: STS, steroid sulfatase; RFS, recurrence-free survival; CSS, cancer-specific survival; AR, androgen receptor; DHT, dihydrotestosterone; EMEM, Eagle's minimum essential medium; MIBC, muscle-invasive bladder cancer; NMIBC, non-muscle-invasive bladder cancer

Key words: steroid sulfatase, recurrence-free survival, cancer-specific survival, bladder cancer, epithelial-mesenchymal transition

\section{Introduction}

Males have a higher incidence of bladder cancer than females (1). Although cigarette smoking and occupational exposure to chemicals are the common risk factors associated with the development of bladder cancer, the higher incidence in males cannot be fully explained even after adjustment for these carcinogenic factors (2-4). Recent findings have suggested that androgen signals could account, in part, for the gender difference in bladder cancer incidence (5-7). Androgen receptor (AR) and dihydrotestosterone (DHT) are the most important factors in androgen signals. Although in vitro and animal studies have demonstrated that AR serves an important role in bladder cancer $(6,7)$, no significant association was observed between AR expression and pathological stage, grade or outcome of bladder cancer in a recent multi-institute study (8). DHT has also been demonstrated to promote the growth of bladder cancer cells both in vitro and in animals $(6,9)$, but there is no report on the expression of enzymes involving the formation of DHT in patients with bladder cancer.

Dehydroepiandrosterone is one of the sources of DHT, which is converted from dehydroepiandrosterone sulfate by steroid sulfatase (STS) (10). Dehydroepiandrosterone, having higher circulating concentration and longer half-life in blood, acts as a central reservoir for the formation of biologically active androgens via the action of tissue STS (10). Inhibition of STS may be a novel approach to block the formation of steroids with potent androgenic property; STS has also been suggested to be a therapeutic target for androgen-dependent cancer, such as prostate cancer $(11,12)$, in which STS expression was observed in $85 \%$ of cancer tissues, but not in normal tissues (13). To the best of our knowledge the expression of STS in bladder cancer has not yet been studied. The purpose of the present study was to determine the clinical and functional signification of STS in bladder cancer.

\section{Materials and methods}

Patients. Immunohistochemical analysis was performed on samples from 114 patients with urothelial carcinoma, who were treated for bladder cancer by radical cystectomy at Osaka City University Hospital between January 1995 to December 2015. 
The clinicopathological characteristics of the patients are summarized in Table I. There were 89 male and 25 female patients, and the median age was 69 years (range, 33-84 years). Patients who were either incompletely resected, or histologically confirmed as small cell carcinoma of the bladder, or lost to follow-up, were excluded from the study. Pathologic staging was performed according to the 2009 Tumor, Node, Metastasis classification system (14), and grading was done according to the criteria by the World Health Organization, 2004 (15). The Institutional Review Board at Osaka City University Graduate School of Medicine approved the use of the specimens and clinical data in accordance with the Declaration of Helsinki and guidelines of Osaka City University Graduate School of Medicine (study approval no. 1955). All 114 patients included in the present study provided written informed consent for the collection and use of tissue samples and for the publication of their results.

Immunohistochemical analysis of STS, E-cadherin and vimentin in bladder cancer tissues. Tissues obtained by radical cystectomy were fixed with $10 \%$ formalin for $24-48 \mathrm{~h}$ at room temperature and paraffin-embedded. Paraffin embedding was performed as follow: $100 \%$ ethanol $\left(4 \times 1.5 \mathrm{~h}\right.$ at $\left.37^{\circ} \mathrm{C}\right), 100 \%$ ethanol $\left(2 \times 2 \mathrm{~h}\right.$ at $\left.37^{\circ} \mathrm{C}\right), 100 \%$ ethanol $\left(3 \mathrm{~h}\right.$ at $\left.37^{\circ} \mathrm{C}\right), 100 \%$ xylene $\left(3 \times 30 \mathrm{~min}\right.$ at $\left.35^{\circ} \mathrm{C}\right)$, paraffin wax $\left(2 \times 30 \mathrm{~min}\right.$ at $\left.58^{\circ} \mathrm{C}\right)$, paraffin wax $\left(30 \mathrm{~min}\right.$ at $\left.59^{\circ} \mathrm{C}\right)$, paraffin wax $\left(30 \mathrm{~min}\right.$ at $\left.60^{\circ} \mathrm{C}\right)$ and embedding of the tissues into paraffin blocks. Tissues were cut into $3-\mu \mathrm{m}$ sections for histological analysis. Tissues were stained with Mayer's hematoxylin solution for $5 \mathrm{~min}$ and counterstained in eosin $\mathrm{Y}$ ethanol solution for 3-5 min both at room temperature. Formalin-fixed, paraffin-embedded tissues of bladder cancer were analyzed by immunohistochemical staining as described previously $(4,16)$. Sections were incubated with rabbit polyclonal antibody to STS (HPA 002904; 1:100; Sigma-Aldrich; Merck KGaA, Darmstadt, Germany), rabbit polyclonal antibody to E-cadherin (sc-7870; 1:100; Santa Cruz Biotechnology, Inc., Dallas, TX, USA) and rabbit monoclonal antibody to vimentin (D21H3; 1:100; Cell Signaling Technology, Inc., Danvers, MA, USA) at $4^{\circ} \mathrm{C}$ overnight. This was followed by incubation with biotinylated goat anti-rabbit IgG (BA-4000; 1:200; Vector Laboratories, Inc., Burlingame, CA, USA) for $30 \mathrm{~min}$ at room temperature. Immunoreactivity was detected using a VECSTAIN Elite ABC kit (PK-6101; Vector Laboratories, Inc.) and 3,3'-diaminobenzidine hydrochloride (Sigma-Aldrich, St Louis, MO, USA).

Immunohistochemical analysis was performed by three pathologists. Immunoreactivity of STS was observed in the cytoplasm of bladder cancer cells, but not in normal urothelium. A benign prostate tissue, which was simultaneously removed at the time of radical cystectomy, was used as a positive control. Tissues with $>5 \%$ cancer cells immunoreactive for STS were defined as positive (17). Evaluation of staining for E-cadherin and vimentin were performed based on a staining index $(18,19)$.

Cell lines. The human bladder cancer cell lines (5637, HT1376, UMUC3, TCCSUP and T24) and prostate cancer cell lines (LNCaP and PC-3) were purchased from the American Tissue Culture Collection (Manassas, VA, USA). Cells were authenticated by short tandem repeat analysis performed by
Table I. Patients' characteristics and steroid sulfatase expression $(n=114)$.

\begin{tabular}{|c|c|c|}
\hline Characteristic & $\begin{array}{l}\text { Steroid sulfatase- } \\
\text { positive tumors, n (\%) }\end{array}$ & P-value \\
\hline Age, years & & 0.758 \\
\hline$<65(\mathrm{n}=30)$ & $7(23.3)$ & \\
\hline$\geq 65(n=84)$ & $22(26.2)$ & \\
\hline Sex & & 0.852 \\
\hline Male $(n=89)$ & $23(25.8)$ & \\
\hline Female $(\mathrm{n}=25)$ & $6(24.0)$ & \\
\hline Pathological Stage & & 0.003 \\
\hline $\mathrm{pTa}+\mathrm{pT} 1+\mathrm{pTis}(\mathrm{n}=52)$ & $6(11.5)$ & \\
\hline $\mathrm{pT} 2+\mathrm{pT} 3+\mathrm{pT} 4(\mathrm{n}=62)$ & $23(37.1)$ & \\
\hline Grade & & 0.561 \\
\hline Low $(n=11)$ & $2(18.2)$ & \\
\hline High $(n=103)$ & $27(26.2)$ & \\
\hline Lymph node involvement & & 0.065 \\
\hline Yes $(n=13)$ & $6(46.2)$ & \\
\hline No $(n=101)$ & $23(22.6)$ & \\
\hline Neoadjuvant chemotherapy & & 0.844 \\
\hline Yes $(n=45)$ & $11(24.4)$ & \\
\hline No $(n=69)$ & $18(26.1)$ & \\
\hline Smoking history & & 0.648 \\
\hline Yes $(n=47)$ & $13(27.7)$ & \\
\hline No $(n=67)$ & $16(23.9)$ & \\
\hline
\end{tabular}

Takara Bio, Inc. (Otsu, Japan) and tested to ensure that they were mycoplasma-free by DDC Medical (Thermo Fisher Scientific, Inc., Waltham, MA, USA) in November 2017. Cells were maintained as monolayer cultures at $37^{\circ} \mathrm{C}$ and $5 \% \mathrm{CO}_{2}$. The 5637 cell line was grown in RPMI-1640 (Sigma-Aldrich; Merck KGaA) supplemented with $10 \%$ fetal bovine serum (FBS) (Sigma-Aldrich; Merck KGaA), 1\% HEPES, and 1\% D-Glucose. HT-1376 was grown in Eagle's minimal essential medium (EMEM; Wako Pure Chemical Industries, Ltd., Osaka, Japan) supplemented with $10 \%$ FBS, $1 \%$ sodium pyruvate solution (Sigma-Aldrich; Merck KGaA) and 1\% MEM non-essential amino acid solution (Thermo Fisher Scientific, Inc.). UMUC3 and TCCSUP were grown in EMEM, LNCaP and PC-3 in RPMI 1640, and T24 in McCoy's 5A medium (Thermo Fisher Scientific, Inc.), supplemented with 10\% FBS.

Reverse transcription-quantitative polymerase chain reaction $(R T-q P C R)$. Total RNA was extracted from cell lines using RNeasy Mini kit (Qiagen GmbH, Hilden, Germany) according to the manufacturer's instructions. RT-qPCR assay was performed as described previously (4). The catalogue numbers for the primers used for qPCR were as follows: STS, Hs00996676_m1; E-cadherin, Hs01023894_m1; Vimentin, Hs00185584_m1; GAPDH, Hs00266705_g1 (Applied Biosystems; Thermo Fisher Scientific, Inc.). The thermocycling conditions were: $20 \mathrm{sec}$ at $95^{\circ} \mathrm{C}$ followed by 40 cycles of $3 \mathrm{sec}$ at $95^{\circ} \mathrm{C}$ and $30 \mathrm{sec}$ at $60^{\circ} \mathrm{C}$. Data were then quantified using 
A

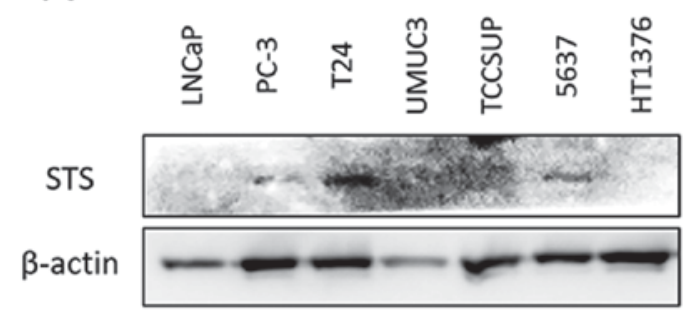

B

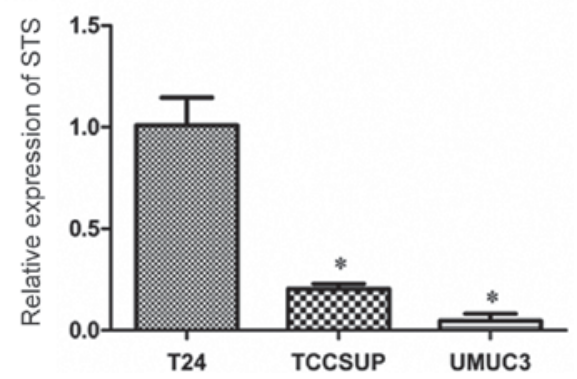

Figure 1. Expression of STS in prostate cancer and bladder cancer cell lines. (A) Protein expression levels of STS are presented in prostate cancer and bladder cancer cell lines. (B) mRNA expression levels of STS are presented in T24, TCCSUP, and UMUC3 cells. Relative STS expression levels have been normalized to those in T24 cells. Data are presented as the mean \pm standard deviation. ${ }^{*} \mathrm{P}<0.01$ vs. T24 cells. STS, steroid sulfatase.

the $2^{-\Delta \Delta \mathrm{Cq}}$ method for relative gene expression (20), compared to that of GAPDH as internal control.

Western blot analysis. Western blotting was performed as previously described (4). Primary antibodies for STS $(1: 1,000)$ and $\beta$-actin (ab8226; 1:1,000; Abcam, Cambridge, UK) were used for the present study. Goat anti-rabbit horseradish peroxidase (HRP)-conjugated IgG and goat anti-mouse HRP-conjugated IgG (nos. sc-2004 and sc-2005; 1:10,000; Santa Cruz Biotechnology) were used as secondary antibodies. Immunoreactive bands were visualized using ECL Prime Western Blotting Detection reagent (GE Healthcare, Chicago, IL, USA).

Knockdown of STS. STS expression was transiently knocked down in T24 cells using Lipofectamine ${ }^{\mathrm{TM}}$ RNAiMAX (Invitrogen; Thermo Fisher Scientific, Inc.) according to the manufacturer's instructions. STS-specific small interfering (si)RNAs (Silencer ${ }^{\circledR}$ Select siRNAs) were obtained from Thermo Fisher Scientific, Inc. The sense sequences of siRNA for STS were as follows: si-STSA, 5'-CUAGCAACAUGG ACAUAUUTT-3'; and si-STS B, 5'-GGACAUAUUUCCUAC AGUATT-3'. Non-targeting control siRNA (cat. no. 4390844; Silencer ${ }^{\circledR}$ Select Negative Control siRNA) was obtained from Thermo Fisher Scientific, Inc. T24 cells $\left(1.5 \times 10^{5}\right)$ were transiently transfected with $10 \mathrm{nM}$ si-STS A, si-STS B, or control siRNA in a 6-well plate. Following 48 h, cells were trypsinized and used in additional assays.

Cell viability assay. To investigate the effect of STS knockdown on cell proliferation, transfectants $\left(1 \times 10^{4} /\right.$ well $)$ were seeded in a 96-well plate and grown in McCoy's 5A medium supplemented with $10 \% \mathrm{FBS}$ at $37^{\circ} \mathrm{C}$ with $5 \% \mathrm{CO}_{2}$. After $48 \mathrm{~h}$, cell proliferation was measured using a Cell Counting Kit-8 (Dojindo Molecular Technologies, Inc., Kumamoto, Japan) according to the manufacturer's instructions. The number of cells was measured using a microplate reader (Bio-Rad Laboratories, Inc., Hercules, CA, USA) at $450 \mathrm{~nm}$.

Cell migration and invasion assay. Migration assay was performed using a Cell Culture Insert with an $8.0-\mu \mathrm{m}$ pore size PET filter (BD Biosciences, Franklin Lakes, NJ, USA) and invasion was assessed via a Matrigel invasion assay (BD Biosciences), according to the manufacturer's protocol. Briefly, $2-3 \times 10^{4}$ cells in $500 \mu \mathrm{l}$ serum-free McCoy's 5A medium were seeded in the upper chamber, whereas the lower chamber was loaded with medium containing $10 \%$ FBS. Following a 24-h incubation at $37^{\circ} \mathrm{C}$, the cells that remained inside the inserts were removed with cotton swabs, and those that migrated or invaded the reverse side of the inserts were fixed with $5 \%$ glutaraldehyde for $15 \mathrm{~min}$ and stained with Giemsa for $30 \mathrm{~min}$ both at room temperature. The cells that had migrated or invaded through the membranes were counted by light microscopy (magnification, x20).

Statistical analysis. Statistical analyses were performed with GraphPad Prism 7 (GraphPad Software, Inc., La Jolla, CA, USA). Fisher's exact test was used to evaluate the differences in incidence of STS expression patterns among clinical and pathological parameters. The recurrence-free survival was defined as the time between the date of surgery and the last date of follow-up or the date of recurrence. The curves were analyzed using the Kaplan-Meier method with the log-rank test to assess statistical significance. For multiple analyses, Cox proportional hazards analysis was used to determine the relative contribution of various factors to the risk of progression. One-way ANOVA followed by a Sidak's post hoc test was used to assess the difference between the in vitro assays. $\mathrm{P}<0.05$ was considered to indicate a statistically significant difference.

\section{Results}

Expression of STS, E-cadherin and vimentin in cell lines and bladder cancer samples. Western blot analysis demonstrated a strong expression of STS in T24 cells, and a weak expression in PC-3 and 5637 cells, compared with those in other cell lines (Fig. 1A). The mRNA expression levels of STS were analyzed by RT-qPCR in three bladder cancer cell lines with invasive characteristics, T24, TCCSUP and UMUC3 cells (Fig. 1B). The expression level of STS was significantly higher in T24 cells than in TCCSUP and UMUC3 cells; therefore, T24 was selected for an in vitro knockdown assay.

Immunohistochemical analysis of STS was performed using 114 formalin-fixed, paraffin-embedded tissues from patients with bladder cancers (Fig. 2). Normal urothelium (Fig. 2A and D), non-invasive bladder cancer (Fig. 2B and E) and invasive bladder cancer (Fig. 2C and F) were compared with benign prostate tissue (Fig. 2G) as a positive control of STS. Immunoreactivity of STS was observed in the cytoplasm of bladder cancer cells in invasive areas of cancer (Fig. 2E), but not 
A

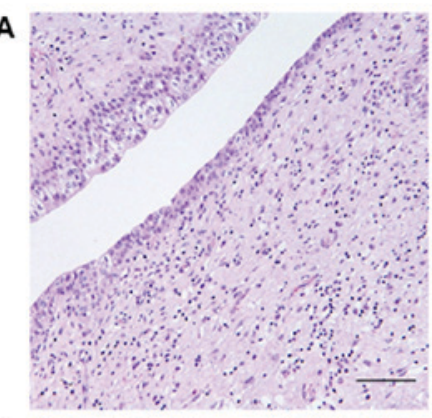

D

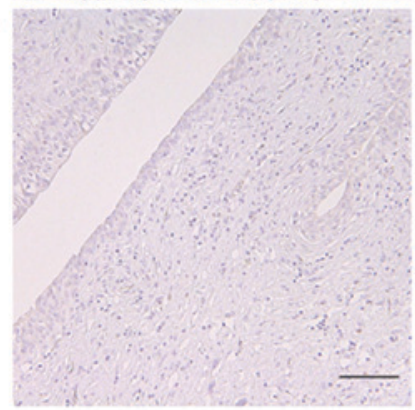

G

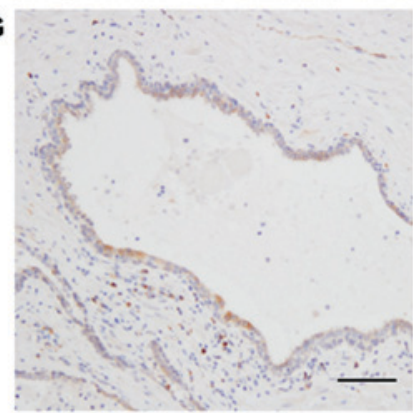

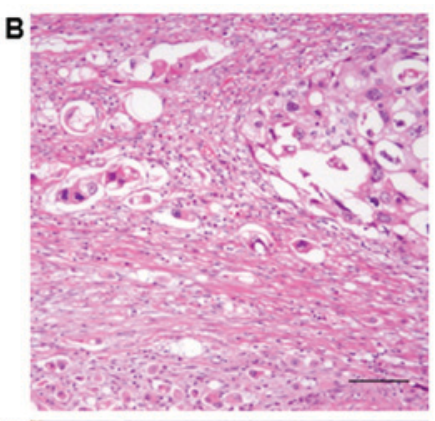

E

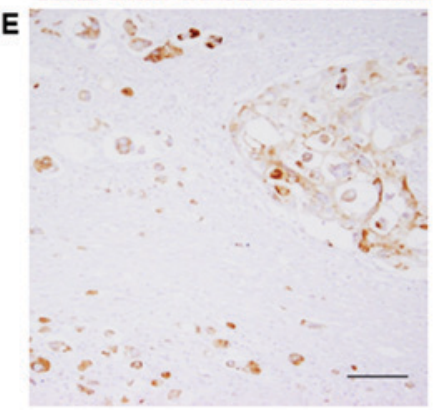

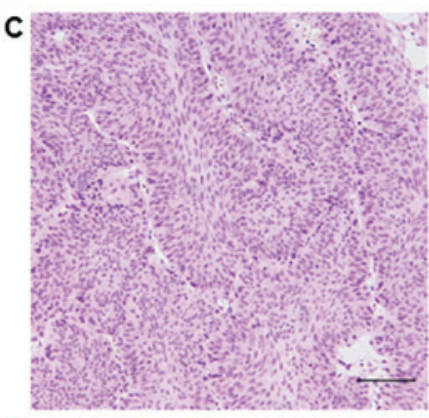

$\mathbf{F}$

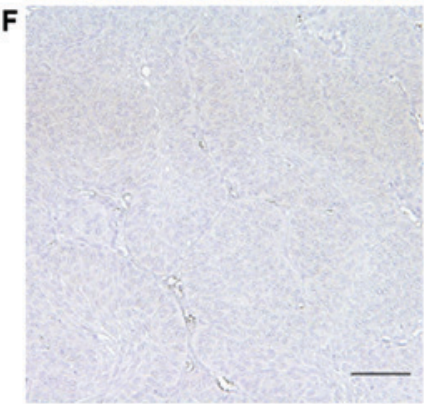

Figure 2. (A-C) Hematoxylin and eosin staining and (D-G) immunohistochemical staining of STS in bladder cancer tissues. STS was not expressed in either (A and D) normal urothelium or (C and F) non-muscle invasive bladder cancer tissues, but was highly expressed in (B and E) the cytoplasm of invasive bladder cancer cells. (G) Benign prostate tissue was used as a positive control. Scale bar indicates $100 \mu \mathrm{m}$. STS, steroid sulfatase.

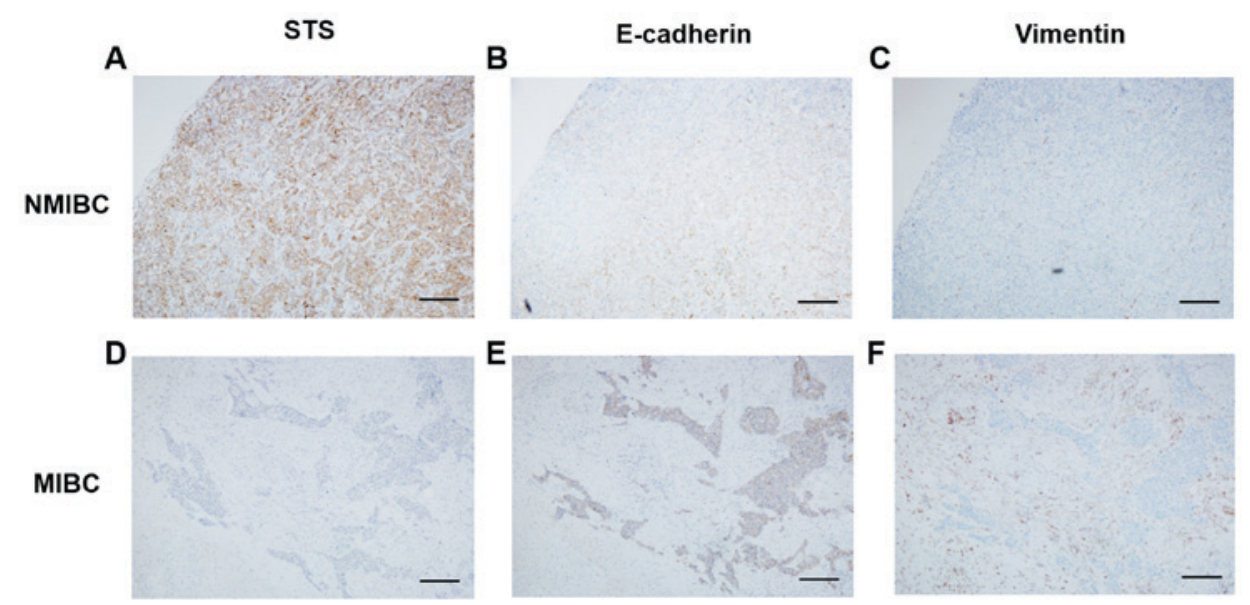

Figure 3. Expressions of STS, E-cadherin and vimentin in bladder cancer tissues. Representative staining is presented for (A-C) NMIBC and (D-F) MIBC. In an NMIBC tissue that was (A) positive for STS, (B) E-cadherin was positive and (C) vimentin was negative. In the other MIBC tissue that was (D) negative for STS, (E) E-cadherin was positive and (F) vimentin was negative. In many of the tissues, E-cadherin was positive and vimentin was negative regardless of the status of the positivity of STS and muscle-invasiveness. Scale bar indicates $200 \mu \mathrm{m}$. STS, steroid sulfatase; NMIBC, non-muscle-invasive bladder cancer; MIBC, muscle-invasive bladder cancer.

in the surface regions, especially in papillary tumors (Fig. 2F). As summarized in Table I, the incidence of STS-positive cancers was significantly higher in muscle invasive bladder cancers (MIBCs; pT2 + pT3 + pT4; 37.1\%) than in non-muscle invasive bladder cancers (NMIBCs; pTa + pT1 + pTis; 11.5\%). No significant association was demonstrated with age or sex. Immunohistochemical analyses of E-cadherin and vimentin were performed using 10 NMIBC and 10 MIBC tissues to 
Table II. Association between steroid sulfatase and epithelial-mesenchymal transition-related factors by immunohistochemical analysis of E-cadherin and vimentin in non-muscle-invasive bladder cancer $(n=10)$ and muscle-invasive bladder cancer $(n=10)$.

A, Steroid sulfatase positive cancers

\begin{tabular}{lcc}
\hline Parameter & Cancer incidence, $\mathrm{n}(\%)$ & P-value \\
\hline E-cadherin & & 0.531 \\
Positive $(\mathrm{n}=17)$ & $1(52.9)$ & \\
Negative $(\mathrm{n}=3)$ & & 0.224 \\
Vimentin & $2(100)$ & \\
Positive $(\mathrm{n}=2)$ & $10(55.6)$ & \\
Negative $(\mathrm{n}=18)$ & & \\
\hline
\end{tabular}

$\mathrm{B}$, Muscle invasive bladder cancers

\begin{tabular}{lcc}
\hline Parameter & Cancer incidence, $\mathrm{n}(\%)$ & P-value \\
\hline E-cadherin & $7(41.2)$ & 0.0603 \\
Positive $(\mathrm{n}=17)$ & $3(100)$ & \\
Negative $(\mathrm{n}=3)$ & & 0.136 \\
Vimentin & $2(100)$ & \\
Positive $(\mathrm{n}=2)$ & $8(44.4)$ & \\
Negative $(\mathrm{n}=18)$ & & \\
\hline
\end{tabular}

NS, not significant.

analyze the association between STS and these EMT-related factors (Fig. 3). The expression of E-cadherin was positive in $85 \%(17 / 20)$ of tissues, while vimentin was negative in $90 \%$ (18/20). There was no statistical significance in the positivity of E-cadherin and vimentin between NMIBCs and MIBCs. Also, no significant association was observed in the expression between STS and these EMT-related markers (Table II).

Follow-up of outcome in patients and survival analysis. Correlation analysis of STS expression with clinical outcomes in 114 patients with bladder cancer revealed worse survival rates in patients with STS-positive cancer. Patients with STS-positive cancer exhibited shorter recurrence-free survival [RFS; Fig. 4A; hazard ratio $(\mathrm{HR})=3.037 ; \mathrm{P}=0.0027$ ] and cancer-specific survival (CSS; Fig. 4B; HR=3.209; $\mathrm{P}=0.003$ ) than those with STS-negative cancers. For patients treated with radical cystectomy, univariate analyses of clinicopathological parameters and RFS or CSS revealed the pathological stage (NMIBC vs. MIBC), lymph node metastasis and STS expression as the major risk factors (Table III). Multivariate analysis demonstrated that stage (MIBC vs. NMIBC) and positive lymph node involvement were independent risk factors for RFS, and stage (MIBC vs. NMIBC) was the only independent risk factor for CSS (Table IV).

Effect of STS knockdown on cell proliferation, migration, and invasion of bladder cancer cells. STS-specific siRNA reduced

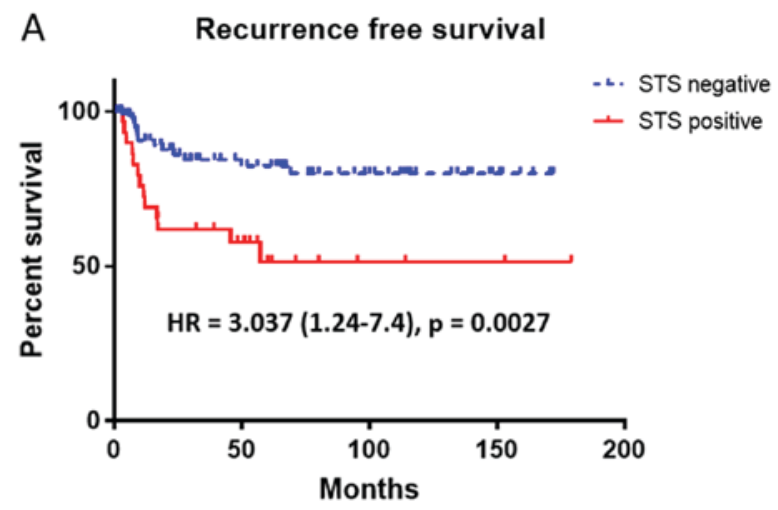

B Cancer specific survival

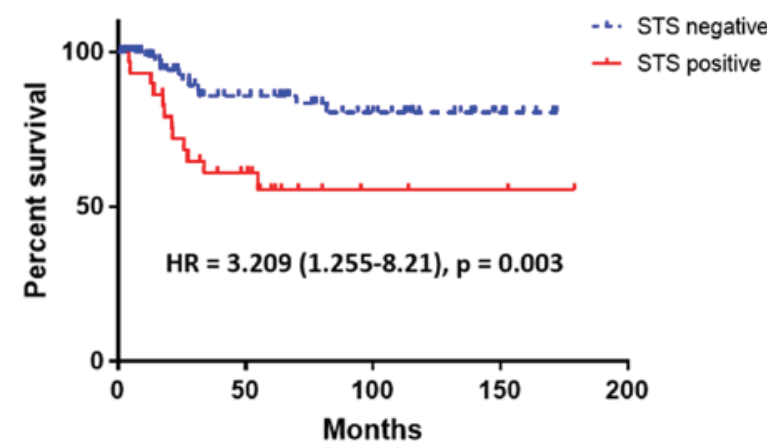

Figure 4. RFS and CSS in patients treated with radical cystectomy $(n=114)$. STS-positive cancers exhibited shorter (A) RFS and (B) CSS. RFS; recurrence-free survival, CSS; cancer-specific survival; STS, steroid sulfatase.

STS mRNA expression levels by $86-90 \%$ compared with that in the negative control cells (Fig. 5A). Knockdown of STS did not significantly affect cell proliferation (Fig. 5B), but significantly inhibited cell migration (35-80\%; Fig. 5C) and invasion (66-73\%; Fig. 5D).

Effect of STS knockdown on the expression of E-cadherin and vimentin. Total RNA was extracted from T24 cells transfected with negative control siRNA, si-STS A or si-STS B. RT-qPCR demonstrated that expression of E-cadherin was significantly upregulated (fold change, 6.75-6.77) and that of vimentin was significantly downregulated (fold change, 0.44-0.60) by STS knockdown (Fig. 5E and F).

\section{Discussion}

In the present study, it was demonstrated that the level of STS expression was significantly higher in MIBCs than in NMIBCs. It was also demonstrated that STS-positive bladder cancers exhibited shorter RFS and CSS. Furthermore, knockdown of STS inhibited cell migration and invasion of bladder cancer cells, via the regulation of E-cadherin and vimentin. To the best of our knowledge, the present study is the first to demonstrate the association between STS expression and invasion/progression of bladder cancers.

Epithelial-mesenchymal transition (EMT) is the critical process of invasion by which epithelial cells lose their intracellular adhesion and acquire a mesenchymal phenotype (21). Loss of E-cadherin is the most well known change during 
Table III. Univariate analyses of clinicopathological parameters and the survivals of patients who were treated with radical cystectomy ( $\mathrm{n}=114)$.

\begin{tabular}{llrlrr}
\hline & \multicolumn{2}{c}{ Recurrence-free survival } & & \multicolumn{2}{c}{ Cancer-specific survival } \\
\cline { 2 - 3 } Variable & \multicolumn{1}{c}{ HR $(95 \% \mathrm{CI})$} & P-value & & HR (95\% CI) & P-value \\
\hline Stage & $5.977(2.769-12.900)$ & 0.0002 & & $7.25(3.199-16.430)$ & 0.0002 \\
Grade & $1.393(0.396-4.907)$ & 0.6504 & & $1.44(0.411-5.051)$ & 0.6195 \\
Lymph node involvement & $5.117(1.369-19.130)$ & $<0.0001$ & & $5.439(1.298-22.800)$ & $<0.0001$ \\
STS & $3.037(1.247-7.400)$ & 0.0027 & & $3.209(1.255-8.210)$ & 0.0030 \\
Neoadjuvant chemotherapy & $2.837(1.248-6.447)$ & 0.0057 & & $2.802(1.381-5.683)$ & 0.0015 \\
Smoking history & $1.067(0.470-2.424)$ & 0.8049 & & $1.471(0.750-2.886)$ & 0.2433 \\
\hline
\end{tabular}

HR, hazard ratio; CI, confidence interval; STS, steroid sulfatase.

Table IV. Multivariate analyses of clinicopathological parameters and the survival of patients who were treated with radical cystectomy ( $\mathrm{n}=114)$.

\begin{tabular}{|c|c|c|c|c|}
\hline \multirow[b]{2}{*}{ Variable } & \multicolumn{2}{|c|}{ Recurrence-free survival } & \multicolumn{2}{|c|}{ Cancer-specific survival } \\
\hline & HR (95\% CI) & P-value & $\mathrm{HR}(95 \% \mathrm{CI})$ & P-value \\
\hline Stage & $4.686(1.547-14.203)$ & 0.0063 & $10.004(1.259-79.474)$ & 0.0294 \\
\hline Lymph node involvement & $2.8716(1.287-6.410)$ & 0.01 & $2.023(0.691-5.919)$ & 0.1983 \\
\hline STS & $1.2496(0.857-1.823)$ & 0.2472 & $1.4753(0.895-2.436)$ & 0.1285 \\
\hline
\end{tabular}

HR, hazard ratio; CI, confidence interval; STS, steroid sulfatase.
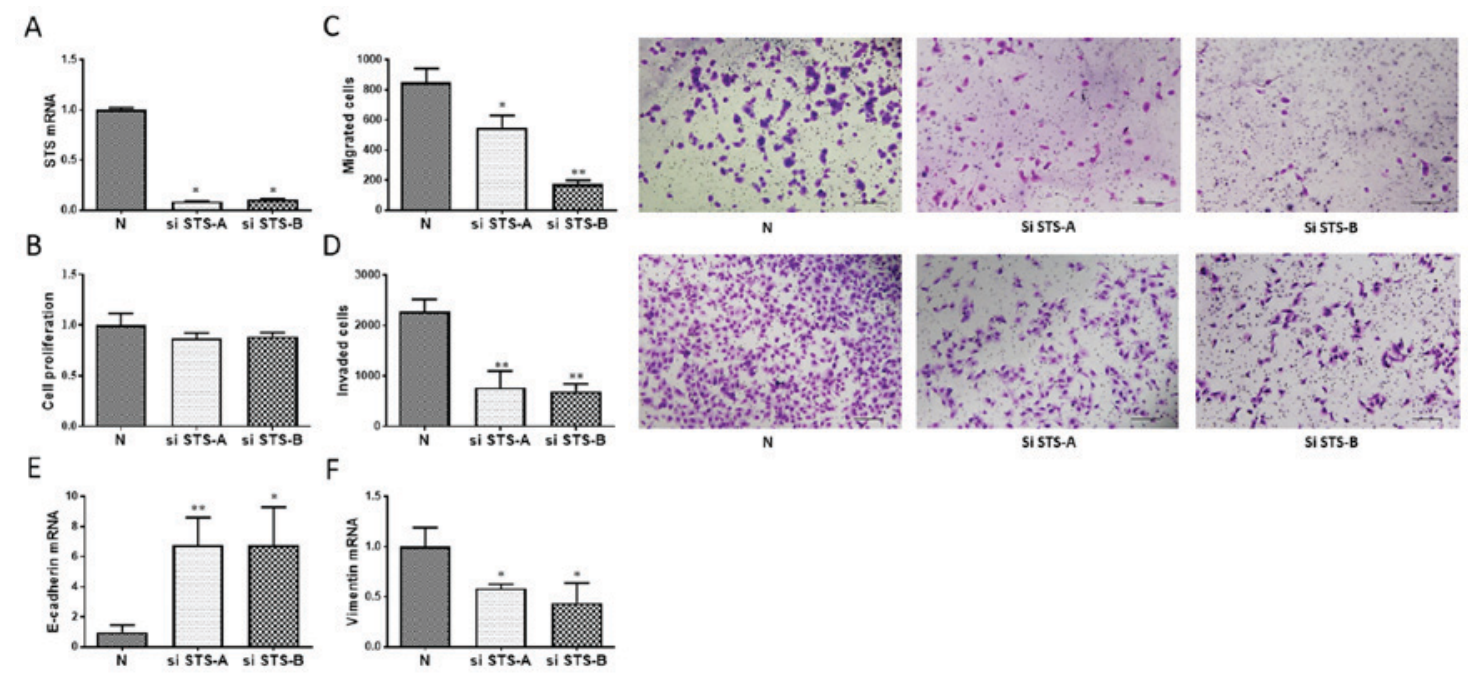

Figure 5. Effect of STS knockdown in T24 cells. (A) Two siRNAs for STS (si-STS A and si-STS B) reduced mRNA expression of STS in T24 cells. Relative STS expression levels are presented normalized to those in N cells. (B) Effect of siRNA knockdown on cell proliferation was evaluated using T24 cells. Each cell count was normalized to that of the $\mathrm{N}$ group. No significant difference was observed between si-STS-transfected and N cells. Effect of siRNA knockdown on cell migration and invasion ability was also evaluated using T24 cells. si-STS A- and B-transfected cells exhibited significantly reduced (C) migration and (D) invasion abilities compared with N cells. Scale bar indicates $500 \mu \mathrm{m}$. (E and F) Reverse transcription-quantitative polymerase chain reaction analyses of T24 cells transfected with siRNAs. Each gene expression level was normalized to that in N cells. (E) E-cadherin was upregulated and (F) vimentin was significantly downregulated by STS knockdown. ${ }^{*} \mathrm{P}<0.05$ and ${ }^{* *} \mathrm{P}<0.01$ vs. negative control.. siRNA, small interfering RNA; STS, steroid sulfatase; si-STS, STS siRNA; N, negative control.

EMT. In contrast, mesenchymal markers such as vimentin, induce EMT (22). In a study by McConkey et al, a strong inverse correlation was observed between the expression of E-cadherin and vimentin in bladder cancer (23). The present 
study demonstrated that knockdown of STS inhibited the invasion capacities of bladder cancer cells accompanied by the upregulation of E-cadherin and downregulation of vimentin, thereby suggesting that STS promoted invasion of bladder cancer by modifying EMT.

A major limitation of the present study, however, is the small sample size. STS could not be indicated as an independent prognostic factor for CSS of the patients with bladder cancer due to the small number of cancer-specific mortalities. Also, the association of STS and EMT-related markers could not be demonstrated by immunohistochemistry. Unexpectedly, E-cadherin was positive in $70 \%$ and vimentin was negative in $80 \%$ of MIBC tissues. Alteration of the expression levels of E-cadherin and vimentin might not occur simultaneously with the expression of STS in the tissue of bladder cancer cells. To clarify the significance of STS expression in clinical outcomes, further research is required. Another limitation of the present study was that it could not demonstrate whether the role of STS in bladder cancer invasion was dependent on androgen/DHT signaling. Accordingly, further study on the interaction network between STS and AR would elucidate the behavior of STS in EMT.

With respect to the mechanism underlying the upregulation of STS in cancers, Suh et al reported that phosphatidylinositol 3 -kinase/protein kinase $\mathrm{B}$ activation mediates the induction of STS expression by tumor necrosis factor- $\alpha$ in human prostate and breast cancer cells (24). Hughes et al previously reported that stimulation of the extracellular signal-regulated kinase (ERK)/mitogen-activated protein kinase (MAPK) pathways by $1 \alpha, 25$-dihydroxyvitamin D3 may contribute to the increase in STS expression (25). Shin et al reported that STS induced Wnt/ $\beta$-catenin signaling and EMT transition in human prostate and cervical cancer cells (26). Further studies to evaluate phosphatidylinositol 3-kinase/protein kinase B and ERK/MAPK pathways would facilitate a better understanding of the role of STS in invasive bladder cancer. In conclusion, the present study demonstrates that STS could promote the invasion capability of bladder cancer via regulating EMT, and could be a useful marker for predicting the progression of bladder cancers and a novel target for clinical therapy.

\section{Acknowledgements}

The authors are grateful to Ms. Rie Onodera, Ms. Kaori Nakakubo, Ms. Azusa Inagaki, Ms. Keiko Sakata and Ms. Yuko Hisabayashi (Department of Pathology, Osaka City University, Osaka, Japan) for their technical assistance and to Ms. Yukiko Iura (Deptartment of Pathology, Osaka City University, Osaka, Japan) for her assistance in preparing this manuscript.

\section{Funding}

The present study was supported in part by a grant from Grants-in-Aid for Scientific Research (grant no. 24592406), from Japan Society for the Promotion of Science.

\section{Availability of data and materials}

The datasets used and/or analyzed during the current study are available from the corresponding author on reasonable request.

\section{Authors' contributions}

MK, HW, ST and MG were responsible for the conception and design of the present study; YS, MK, MF, AK and YT were responsible for the acquisition of data; and YS, MK, HW, TN and $\mathrm{MG}$ were responsible for the analysis and/or interpretation of data.

\section{Ethics approval and consent to participate}

The Institutional Review Board at Osaka City University Graduate School of Medicine (Osaka, Japan) approved the use of the specimens and clinical data in accordance with the Declaration of Helsinki and guidelines of Osaka City University Graduate School of Medicine (study approval no. 1955). All 114 patients provided written informed consent for the collection and use of their samples for the present study.

\section{Patient consent for publication}

All 114 patients included in this study provided written informed consent for the publication of their results.

\section{Competing interests}

The authors declare that they have no competing interests.

\section{References}

1. Siegel R, Ward E, Brawley O and Jemal A: Cancer statistics, 2011: The impact of eliminating socioeconomic and racial disparities on premature cancer deaths. CA Cancer J Clin 61: 212-236, 2011.

2. Hartge P, Harvey EB, Linehan WM, Silverman DT, Sullivan JW, Hoover RN and Fraumeni JF Jr: Unexplained excess risk of bladder cancer in men. J Natl Cancer Inst 82: 1636-1640, 1990.

3. Hemelt M, Yamamoto H, Cheng KK and Zeegers MP: The effect of smoking on the male excess of bladder cancer: A meta-analysis and geographical analyses. Int J Cancer 124: 412-419, 2009.

4. Kato M, Wei M, Yamano S, Kakehashi A, Tamada S, Nakatani T and Wanibuchi H: DDX39 acts as a suppressor of invasion for bladder cancer. Cancer Sci 103: 1363-1369, 2012.

5. Imada S, Akaza H, Ami Y, Koiso K, Ideyama Y and Takenaka T: Promoting effects and mechanisms of action of androgen in bladder carcinogenesis in male rats. Eur Urol 31: 360-364, 1997.

6. Miyamoto H, Yang Z, Chen YT, Ishiguro H, Uemura $H$, Kubota Y, Nagashima Y, Chang YJ, Hu YC, Tsai MY, et al: Promotion of bladder cancer development and progression by androgen receptor signals. J Natl Cancer Inst 99: 558-568, 2007.

7. Shiota M, Takeuchi A, Yokomizo A, Kashiwagi E, Tatsugami K, Kuroiwa $\mathrm{K}$ and Naito $\mathrm{S}$ : Androgen receptor signaling regulates cell growth and vulnerability to doxorubicin in bladder cancer. J Urol 188: 276-286, 2012.

8. Mir C, Shariat SF, van der Kwast TH, Ashfaq R, Lotan Y, Evans A, Skeldon S, Hanna S, Vajpeyi R, Kuk C, et al: Loss of androgen receptor expression is not associated with pathological stage, grade, gender or outcome in bladder cancer: A large multi-institutional study. BJU Int 108: 24-30, 2011.

9. Johnson AM, O'Connell MJ, Miyamoto H, Huang J, Yao JL, Messing EM and Reeder JE: Androgenic dependence of exophytic tumor growth in a transgenic mouse model of bladder cancer: A role for thrombospondin-1. BMC Urol 8: 7, 2008.

10. Rainey WE, Carr BR, Sasano H, Suzuki T and Mason JI: Dissecting human adrenal androgen production. Trends Endocrinol Metab 13: 234-239, 2002.

11. Selcer KW, Kabler H, Sarap J, Xiao Z and Li PK: Inhibition of steryl sulfatase activity in LNCaP human prostate cancer cells. Steroids 67: 821-826, 2002.

12. Purohit A and Foster PA: Steroid sulfatase inhibitors for estrogen- and androgen-dependent cancers. J Endocrinol 212: 99-110, 2012. 
13. Nakamura Y, Suzuki T, Fukuda T, Ito A, Endo M, Moriya T, Arai Y and Sasano H: Steroid sulfatase and estrogen sulfotransferase in human prostate cancer. Prostate 66: 1005-1012, 2006.

14. Sobin LH and Compton CC: TNM seventh edition: What's new, what's changed: Communication from the International Union Against Cancer and the American Joint Committee on Cancer. Cancer 116: 5336-5339, 2010

15. Montironi R and Lopez-Beltran A: The 2004 WHO classification of bladder tumors: A summary and commentary. Int J Surg Pathol 13: 143-153, 2005.

16. Tachibana H, Gi M, Kato M, Yamano S, Fujioka M, Kakehashi A, Hirayama Y, Koyama Y, Tamada S, Nakatani T and Wanibuchi H: Carbonic anhydrase 2 is a novel invasion-associated factor in urinary bladder cancers. Cancer Sci 108: 331-337, 2017.

17. Lee WM, Jang KS, Bae J and Koh AR: The role of steroid sulfatase as a prognostic factor in patients with endometrial cancer. Yonsei Med J 57: 754-760, 2016.

18. Gravdal K, Halvorsen OJ, Haukaas SA and Akslen L: A switch from $\mathrm{E}$-cadherin to $\mathrm{N}$-cadherin expression indicates epithelial to mesenchymal transition and is of strong and independent importance for the progress of prostate cancer. Clin Cancer Res 13: 7003-7011, 2007

19. Zhang Q, Helfand BT, Jang TL, Zhu LJ, Chen L, Yang XJ, Kozlowski J, Smith N, Kundu SD, Yang G, et al: Nuclear factor-kappaB-mediated transforming growth factor-beta-induced expression of vimentin is an independent predictor of biochemical recurrence after radical prostatectomy. Clin Cancer Res 15: 3557-3567, 2009.

20. Livak KJ and Schmittgen TD: Analysis of relative gene expression data using real-time quantitative PCR and the 2(-Delta Delta C(T)) method. Methods 25: 402-408, 2001.

21. Mendez MG, Kojima S and Goldman RD: Vimentin induces changes in cell shape, motility, and adhesion during the epithelial to mesenchymal transition. FASEB J 24: 1838-1851, 2010
22. Sánchez-Tilló E, Lázaro A, Torrent R, Cuatrecasas M, Vaquero EC, Castells A, Engel P and Postigo A: ZEB1 represses E-cadherin and induces an EMT by recruiting the SWI/SNF chromatin-remodeling protein BRG1. Oncogene 29: 3490-3500, 2010.

23. McConkey DJ, Choi W, Marquis L, Martin F, Williams MB, Shah J, Svatek R, Das A, Adam L, Kamat A, et al: Role of epithelial-to-mesenchymal transition (EMT) in drug sensitivity and metastasis in bladder cancer. Cancer Metastasis Rev 28: 335-344, 2009.

24. Suh BY, Jung JJ, Park N, Seong CH, Im HJ, Kwon Y, Kim D and Chun YJ: Induction of steroid sulfatase expression by tumor necrosis factor- $\alpha$ through phosphatidylinositol 3-kinase/Akt signaling pathway in PC-3 human prostate cancer cells. Exp Mol Med 43: 646-652, 2011.

25. Hughes PJ, Steinmeyer A, Chandraratna RA and Brown G: 1alpha,25-dihydroxyvitamin D3 stimulates steroid sulphatase activity in HL60 and NB4 acute myeloid leukaemia cell lines by different receptor-mediated mechanisms. J Cell Biochem 94: 1175-1189, 2005.

26. Shin S, Im HJ, Kwon YJ, Ye DJ, Baek HS, Kim D, Choi HK and Chun YJ: Human steroid sulfatase induces Wnt/ $\beta$-catenin signaling and epithelial-mesenchymal transition by upregulating Twist1 and HIF-1 $\alpha$ in human prostate and cervical cancer cells. Oncotarget 8: 61604-61617, 2017.

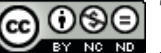

This work is licensed under a Creative Commons Attribution-NonCommercial-NoDerivatives 4.0 International (CC BY-NC-ND 4.0) License. 